\title{
The Co-movement Analysis of A + H Stocks Based on CHMM
}

\author{
Shulan Hu, Xuan Zhang* and Pengfei Tian \\ School of Statistics and Mathematics, Zhongnan University of Economics and Law, Wuhan 430073, China \\ ${ }^{*}$ Corresponding author
}

\begin{abstract}
The implementation of the Shanghai-Hong Kong Stock Connect program and Shenzhen-Hong Kong Stock Connect program mark the gradual opening up of capital account in our financial markets and the relaxation of exchange rate and interest rate control. It makes the arbitrage mechanism of $\mathrm{A}+\mathrm{H}$ stocks, trading strategies and risk management become more flexible and get more attention. We chose the $A+H$ stocks which were listed both in the mainland China and Hong Kong stock market as our research objects. Then, we conducted a co-movement analysis for the current $A+H$ stocks using econometrical methods and statistical model. Finally, taking the stock of China Pacific Insurance and Angang Steel Company Limited as examples, we studied the co-movement of their $\mathrm{A}+\mathrm{H}$ stocks and reasonable trading strategies.
\end{abstract}

Keywords-linkage of price fluctuation; $A+H$ stocks; trading strategy; Coupled Hidden Markov Model

\section{INTRODUCTION}

The Shanghai-Hong Kong Stock Connect program was launched on November 17 th $^{\text {t }} 2014$ in China. Meanwhile, the Shenzhen-Hong Kong Stock Connect program was launched on December $5^{\text {th }}, 2016$. They lead to changes of the co-movement effects for the stocks which were listed in either Shanghai or Shenzhen stock market (A stock market), and Hong Kong stock market (H stock market) at the same time. The enterprises' main bodies of $\mathrm{A}+\mathrm{H}$ stocks are the same, but they are listed in different markets whose economy systems are different. Therefore, it leads to same trend and mutual influence of the price between A stock market and $\mathrm{H}$ stock market. In short terms, it seems that there will be a variance for the price of two markets due to environments of the markets, expectation of the markets and situation of transactions, etc. But the linkage between mainland Chinese capital market and Hong Kong capital market is growing stronger, which can be demonstrated by the appearance of $\mathrm{A}+\mathrm{H}$ stock.

It is significant to deeply analyze the co-movement between A stock market and $\mathrm{H}$ stock market at a time when the Shanghai-Hong Kong Stock Connect program and the Shenzhen-Hong Kong Stock Connect program have already been launched. On a micro level, the research can enable the investigators to make their investigation more efficiently by letting them understand the dynamic linkage between these two markets. On a macro level, the research can help government to better monitor the risks of the markets, efficiently release policies, and accelerate the development and innovation of the Chinese capital market.
There were many researches on the co-movement between two or more stock markets. Hilliard (1979) analyzed the correlation and lag correlation among 10 stock markets in different countries with spectroscopic analysis. Hamao et al. (1990), Karolyi and Stulz (1996), Cheng and Glascock (2005) Albaity and Shanmugam (2012) also studied the price co-movement between different stock markets. Li (2007) established a multi-variables GARCH model in order to find the linkage of stock markets among Shenzhen, Shanghai, Hong Kong and the United States. There weren't any evidences found to demonstrate the direct relationship between Chinese and American stock markets. But they found that Shanghai and Shengzhen stock markets existed one-way volatility spillover effect by Hong Kong stock market. After that, Wu et al. (2013), Lin (2013) et al. analyzed the interaction between Chinese stock market and developed stock markets, in order to predict stock market volatility in some specific backgrounds.

With the opening up of Chinese capital market and the trend of economic integration between Hong Kong and mainland China, there are more researches on the correlation between A stock market and $\mathrm{H}$ stock market. Yan and Cui (2012) used the cointegration test, impulse response function analysis and variance analysis to study the linkage of stock markets between Hong Kong and mainland China. Zhou (2012) analyzed the stock price linkage between Hong Kong and mainland China after the reform of splitting share structure by constructing the VAR model. The results showed that there may be temporary price deviations in the two markets in the short term, but the trend of the stock prices in the two cities is consistent in the long term. Wang (2013) and Zhou (2014) studied the linkage between the Hong Kong and mainland Chinese stock markets before and after the events of QFII, QDII or sub-prime crisis.

Based on former researches, traditional methods are applied to the research of co-movements of $\mathrm{A}+\mathrm{H}$ stocks in this paper. Due to the frequent structural changes in the series of stock prices, we introduce the Hidden Markov Model in which the state series is driven by the hidden Markov process. Since there are some correlation between A and H stock markets, building Hidden Markov Model to analyze the interaction is not accurate. To fix the deficiencies of Hidden Markov Model, we choose the data of closing prices of $\mathrm{A}+\mathrm{H}$, and analyze them by Coupled Hidden Markov Model with two chains. Meanwhile, we verify the feasibility and validity of the proposed method, and propose trading strategies in order to guide the investors to optimize their investment decision. 


\section{A+H CO-MOVEMENT TEST}

\section{A. Data Source}

There are four main prices, which are the opening, lowest, highest and closing price. The closing price reflects the extent of focus on certain stock by all the participants in market, and it can be used to predict the trend in next trading day. The closing prices of HSAHA (Heng Seng AH A Index) and HSAHH (Heng Seng AH H Index), which has a total number of 445, are selected from July 31 ${ }^{\text {th }}, 2013$ to June $15^{\text {th }}$, 2015 in our research.

\section{B. Efficiency Test}

According to the efficient market hypothesis, all markets are divided into three categories, which are the weak form efficient market, semi-strong form efficient market, and strong form efficient market.

TABLE I. THE RESULTS OF ADF TEST FOR HSAHA AND HSAHH

\begin{tabular}{c|c|c|c|c}
\hline \multirow{2}{*}{} & \multicolumn{2}{|c|}{ Original Series } & \multicolumn{2}{c}{ First-Order Difference } \\
\cline { 2 - 5 } & $\begin{array}{c}\text { ADF Test } \\
\text { Statistic }\end{array}$ & $P$ Value & $\begin{array}{c}\text { ADF Test } \\
\text { Statistic }\end{array}$ & $P$ Value \\
\hline HSAHA & 1.0170 & 0.9968 & $-20.6918^{*}$ & 0.0000 \\
\hline HSAHH & -0.3079 & 0.9209 & $-19.8223^{*}$ & 0.0000 \\
\hline Note: * denotes the statistical significance at a confidence level of $95 \%$.
\end{tabular}

HSAHA and HSAHH are chosen as variables in our research, and ADF unit root test is adopted to analyze the efficiency of A stock market and $\mathrm{H}$ stock market. The results are shown in table 1. It shows that after the first order difference, HSAHA and HSAHH series are stationary at a confidence level of $95 \%$.

From the analysis, we can tell that the A stock market in China has already been weak form effective. The reason is that there are a great number of retail investors whose information is not symmetrical, leading to a low efficiency in investment. The facts that the Chinese stock market lacks short-selling mechanism, strong regulatory systems and perfect protection mechanisms for investors also lead to the result. The $H$ stock market was developed earlier and had a more opening system, leading to a better connection with international capital market and free flow of information. All these evidences demonstrate that the $\mathrm{H}$ stock market has a stronger efficiency than A stock market, and $\mathrm{H}$ stock market has already become semi-strong form effective.

\section{Cointegration Test}

The monitoring of market, revealing of information and innovating of finance in Hong Kong are at advanced all over the world. The investors tend to invest more rationally, and focus more on rational investment. In contrast, the investors in Chinese stock market tend to follow the trend and invest blindly. Hence, investors can predict the trend and volatility of the price in A stock market based on the price changes of the same stock in the H stock market.

\section{TABLE II. THE RESULTS OF COINTERGRATION TEST}

\begin{tabular}{c|c|c|c|c|c}
\hline \multirow{2}{*}{$\begin{array}{c}\text { Depende } \\
\text { nt } \\
\text { Variable }\end{array}$} & \multicolumn{2}{|c|}{ Constant Term } & \multicolumn{2}{c|}{$\begin{array}{c}\text { Independent } \\
\text { Variable (HSAHH) }\end{array}$} & $\begin{array}{c}\text { ADF } \\
\text { Statistic of } \\
\text { Residuals }\end{array}$ \\
\cline { 2 - 5 } & Coefficient & $T$ Value & Coefficient & $T$ Value & $-2.8730 *$ \\
\hline HSAHA & $-1569.28 *$ & -32.5202 & $1.7148 *$ & 70.0934 & -140 \\
\hline
\end{tabular}

Note: * denotes the statistical significance at a confidence level of 95\%.
The results are shown in table 2 . It can be concluded that the regression coefficient between independent variable and dependent variable is significant, and the ADF statistic of residuals shows that HSAHA and HSAHH share a long-term stationary changing direction. Economic relations are the foundation of the co-movement between stock markets. Since Hong Kong returned to China, the economic trends of Hong Kong and the mainland China have influenced each other, and have also been reflected in the stock markets.

\section{The A+H Stock Trading Strategy Based on COUPLED HIDDEN MARKOV MODEL}

\section{A. Data Source}

There has been $86 \mathrm{~A}+\mathrm{H}$ stocks, 69 of which were listed in both Shanghai and Hong Kong Stock Exchange, and 17 of which were listed in both Shenzhen and Hong Kong Stock Exchange. The closing prices of Shanghai-Hong Kong listed stocks were collected since July 31 ${ }^{\text {st }}, 2013$ to July $29^{\text {th }}, 2016$. For Shenzhen-Hong Kong listed stocks, the closing prices were collected from January 30 $0^{\text {th }}, 2014$ to January 29 $9^{\text {th }}$, 2015. The data of China Vanke and CNR were eliminated because of the lack of data length, since their Hong Kong stocks were published in the middle of 2014. For eliminating the randomly minor fluctuation in the data, we keep three-day trading data.

\section{B. Correlation Analysis}

In aim of better analyzing the co-movement between $\mathrm{A}$ stock market and $\mathrm{H}$ stock market, we firstly study the correlation relationship of these 84 stocks. The numbers of stocks with different correlation coefficients are shown in table 3.

\section{TABLE III. THE NUMBERS OF STOCKS WITH DIFFERENT} COEFFICIENTS

\begin{tabular}{lcc}
\hline $\begin{array}{c}\text { Correlation } \\
\text { Coefficient }\end{array}$ & Shanghai-Hong Kong & Shenzhen-Hong Kong \\
\hline$>0.8$ & 25 & 5 \\
$0.5 \sim 0.8$ & 28 & 8 \\
$0.3 \sim 0.5$ & 5 & 2 \\
$0.0 \sim 0.3$ & 6 & 1 \\
$<0$ & 4 & 0 \\
\hline
\end{tabular}

According to the analysis results, it can be concluded that the stock markets in mainland China is closely tied to the stock markets in Hong Kong under the background of economic globalization.

\section{Coupled Hidden Markov Model (CHMM)}

1) Hidden Markov Model (HMM): HMM is a significant statistical model that its state sequence is a Markov chain, and the observation variables corresponding to state sequence follow a random distribution. In the past decades, HMM was widely utilized in speech recognition, economics, spectroscopy, biology, etc. in order to analyze the weak correlated random variable sequences. According to the property of the Markov process, the current state of the model is only related to the last state. Given the hidden sequence $\left\{q_{T}\right\}$, the observed sequence ${ }^{\left\{o_{T}\right\}}$ only depends on the current state. The process is described in Figure 1. 


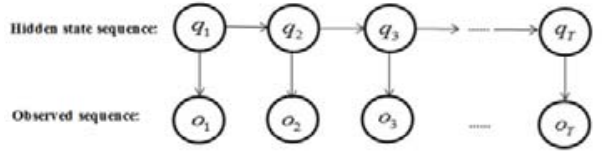

FIGURE I. THE GRAPHICAL REPRESENTATION OF HMM

Every HMM consist of two state sequences and three probability matrix. In general, $\mathrm{S}$ denotes hidden state sequence. $\mathrm{O}$ denotes observable state sequence. $\pi$ denotes the probability distribution of the hidden state at the initial time. A denotes hidden state transition matrix which contains the probability that a hidden state evolve to another hidden state. $B$ denotes the emission probability matrix which contains the probability distributional matrix of the observed states, given the hidden state. HMM which includes the elements mentioned above is usually written as:

$$
\lambda=(\pi, A, B)
$$

2) Coupled Hidden Markov Model: A new model, CHMM, was put forward by Mattew Brand. It reflects the mutual influences among two or more random process, and can be utilized to model several random processes. Figure 2 is the CHMM with two chains. It consists two coupled HMM models. The current state in a HMM is not only influenced by the last state in this HMM, but also affected by the last state in coupled HMM.

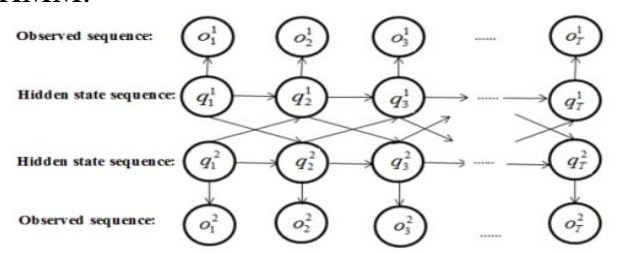

FIGURE II. THE GRAPHICAL REPRESENTATION OF CHMM

In this paper, we take CHMM with two chains as an example, which can be described by the following parameters: $\bar{S}$ denotes hidden state sequence. ${ }^{N_{1}}$ and ${ }^{N_{2}}$ denote the number of hidden states for chain 1 and chain 2 , respectively. $\bar{O}$ denotes observable state sequence. At time $t$, the observed values of chain 1 and chain 2 are $o_{t}^{1}$ and $o_{t}^{2}$. In general, $\bar{o}_{t}=\left\{o_{t}^{1}, o_{t}^{2}\right\}$ denotes the observed value of model at time t. $\bar{\pi}$ denotes initial probability distribution of the hidden state. $\bar{A}$ denotes hidden state transition matrix. $\bar{B}$ denotes emission probability matrix. Similarly, CHMM which includes the elements mentioned above is usually written as:

$$
\bar{\lambda}=(\bar{\pi}, \bar{A}, \bar{B})
$$

3) Forward-Backward Algorithm: In HMM, we often use forward-backward algorithm to effectively calculate the probability of an observable state sequence. We only introduce the forward algorithm in detail. The forward algorithm is a dynamic programming algorithm that produces the observed sequence by computing the sum of all probabilities, but it implicitly superimposes each sequence on a single forward grid, thereby increasing the efficiency.

Firstly, we define the forward variable which can be expressed as: $\alpha_{t, i}=p\left(o_{1}, o_{2}, \ldots, o_{t}, q_{t}=S_{i} \mid \lambda\right)$, where $\alpha_{t, i}$ means the probability distribution of the hidden state $S_{i}$ at time $t$ and the observed sequence $o_{1}, o_{2}, \ldots, o_{t}$, given a model $\lambda$.

Then, we give an iterative formula of the forward algorithm, which states:

a) Initialization: $\alpha_{1, i}=\pi_{i} b_{i}\left(o_{1}\right), \quad 1 \leq i \leq N$.

b) Iteration: $\alpha_{t+1, j}=\left(\sum_{i=1}^{N} \alpha_{t, i} a_{i j}\right) b_{j}\left(o_{t+1}\right), \quad 1 \leq t \leq T-1,1 \leq j \leq N$.

c) End:

$$
p\left(o_{1}, o_{2}, \ldots, o_{T} \mid \lambda\right)=\sum_{i=1}^{N} \alpha_{T, i}
$$

\section{Empirical Analysis of Coupled Hidden Markov Model}

In this paper, the co-movements of a total number of 84 stocks are researched in aim of developing valuable trading strategies. To better describe the structural changes in the stock market, the CHMM is adapted in our research. The first thing is to examine the states of historical transaction data. Due to the complexity of calculation, we only consider the CHMM with two states, which are the ascending and descending state. The notations of every state are shown in table 4.

TABLE IV. THE NOTATION OF STATES

\begin{tabular}{ccc}
\hline The Notation of States & The State for A Stock & The State for H Stock \\
\hline 1 & Ascending & Ascending \\
3 & Ascending & Descending \\
4 & Descending & Ascending \\
\hline
\end{tabular}

And the hidden state transition matrix can be expressed as:

$$
\bar{A}=\left(\bar{p}_{i j}\right)_{i, j=1,2,3,4}
$$

Generally, the state transition matrix A-bar can be estimated based on prior information. The frequency estimation which we mainly used in our research is to utilize the known sample hidden state sequence to roughly approximate the transition probability. If $\bar{A}_{i j}$ represents the frequency of state $i$ transferring to $j$ in the hidden state sequence, we can get $\bar{p}_{i j}=\bar{A}_{i j} / \sum_{j=1}^{N} \bar{A}_{i j}$.

According to the correlation analysis before, we take the stock of China Pacific Insurance (Stock symbol: 601601) and Angang Steel Company Limited (Stock symbol: 000898) as examples. The analyses of other stocks are similar with what have been done for them.

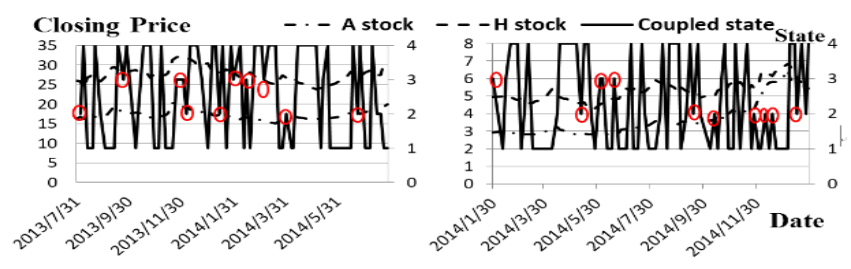

FIGURE III. THE DIAGRAM OF CLOSING PRICE AND COUPLED STATE FOR CHINA PACIFIC INSURANCE (LEFT) AND ANGANG STEEL COMPANY LIMITED (RIGHT) 
Based on the method of determining the state mentioned above, the plot of closing price sequence and coupled state sequence for China Pacific Insurance and Angang Steel Company Limited are shown in Figure 3, respectively. We can tell from the figures that within the sample period, the most common situations are the simultaneous increasing (state 1) and decreasing (state 4) of both $\mathrm{A}$ and $\mathrm{H}$ stock, and there are only a few non-simultaneous time (state 2 or state 3 ).

To better understand more characteristics of these stocks, their coupled transition matrix are shown below:

$$
\bar{A}_{\text {Pacific }}=\left(\begin{array}{llll}
0.53 & 0.07 & 0.1 & 0.3 \\
0.33 & 0.11 & 0 & 0.56 \\
0.22 & 0.11 & 0.22 & 0.45 \\
0.32 & 0.13 & 0.13 & 0.42
\end{array}\right) \quad \bar{A}_{\text {Angang }}=\left(\begin{array}{llll}
0.47 & 0.28 & 0.12 & 0.13 \\
0.47 & 0 & 0 & 0.53 \\
0.5 & 0 & 0.17 & 0.33 \\
0.32 & 0.28 & 0 & 0.4
\end{array}\right)
$$

The sustainability of every state can be analyzed from the matrix. When these two stocks are in state 2 or 3, the sustaining of the state will be less possible. It can also be concluded that A stock and $\mathrm{H}$ stock have a strong positive correlation, which is in accordance with the conclusion in the correlation test. Therefore, investors should focus on the marked time points in Figure 3, where the states are not synchronized. These are the key time of trading.

\section{E. Assessment for Trading Strategy Based on Coupled Hidden Markov Model}

Considering the structural changes of stock price and the certain co-movements between two markets, the state transition matrix of CHMM is chosen to analyze the trend of stock prices. Investors should focus on the moment which states are unsynchronized, and trading strategies should be adjusted with the emergence of the unsynchronized states.

During the time from July 30 $0^{\text {th }}, 2014$ to Dec $18^{\text {th }}, 2014$ which is out from sample period, every trading day is picked with an interval of three days. The actual coupled state sequence for China Pacific Insurance is: 1,4,4,1,1,1,3,4,2,1,4,4,4,4,2,1,4,2,3,1,1,2,2,2,1,4,1,1,1,1,4,4,1.

Similarly, 29 trading days are selected from Jan 30 to June $15^{\text {th }}$, 2015 for Angang Steel Company Limited. The results of analysis show the actual coupled state sequence is: $4,3,2,1,1,1,4,4,2,2,2,4,1,1,1,1,2,1,4,4,1,1,4,1,3,1,2,4,2$.

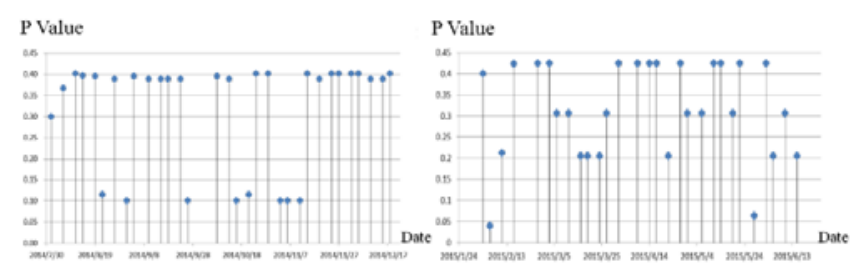

FIGURE IV. THE PROBABILITY OF STATES FOR CHINA PACIFIC INSURANCE (LEFT) AND ANGANG STEEL COMPANY LIMITED (RIGHT)

The actual coupled state sequences within the sample period show that the states of A stock and H stock for China Pacific Insurance and Angang Steel Company Limited are mostly synchronized. When the coupled state 2 or 3 occurs, the next state will be adjusted to a synchronized state, which is mostly in accordance with the prediction from coupled state transition matrix. Figure 4 shows the state probability plot using forward-backward algorithm, and there are only a few moments with a small probability. This demonstrates the accuracy of using CHMM to precisely analysis the property of stock and help investors develop trading strategies.

The analysis of other stocks whose correlation factor is greater than 0.3 show that the application of CHMM can help design more accurate trading strategies, and capture the key trading moments, such as China Railway Group Limited, Dalian Port Company Limited, China Southern Airlines Company Limited, etc. The unsynchronized phenomenon of China Railway Group Limited emerged on Aug $14^{\text {th }}$, Sep $10^{\text {th }}$, $23^{\text {rd }}$, Oct $13^{\text {th }}, 29^{\text {th }}$, Nov $18^{\text {th }}$, Dec $1^{\text {st }}$, etc. And they adjusted to state 1 in a short time. For stocks like Dongjiang Environmental Company Limited, China Molybdenum Company Limited, Beijing North Star Company Limited, etc., the correlation coefficient for these companies is less than 0.3 , and the co-movement is low between their A and H stocks. This means the CHMM is not a very accurate model for setting the trading strategies for these stocks.

\section{CONCLUSION}

The stationary test method is used to demonstrate the A stock market in China has been weak form efficient and the $\mathrm{H}$ stock market in Hong Kong has been semi-strong form efficient. By a further step of correlation analysis, there is a long-term co-movement between A stock market and H stock market. With the implementation of the Shanghai-Hong Kong Stock Connect program and Shenzhen-Hong Kong Stock Connect program, the status of A stock market is getting stronger in international market. The stock market of mainland China will be increasingly influenced by the Hong Kong stock market. Due to all the facts mentioned above, investors should concentrate on the operation of both two markets. For the 73 stocks whose correlation coefficient is greater than 0.3 , introducing CHMM can help investors make accurate trading strategies. The minor moments which the states are unsynchronized should be monitored carefully. Investors should remain calm and carefully analyze the situations in order to optimize their trading strategies.

\section{ACKNOWLEDGMENT}

This paper was funded by the 2017 National Social Science Foundation.

\section{REFERENCES}

[1] M. S. Albaity, and T. Shanmugam, "An analysis of volatility co-movement between Malaysia, US, UK and Japan stock markets,” Asian Journal of Finance \& Accounting, vol. 4(2), pp. 155-179, 2012.

[2] Y. Gu, and L. Lu, "Information spillover effects between HU, SHEN, GANG stock markets and dynamic conditional correlation,” Journal of Quantitative \& Technical Economics, vol. 23(8), pp. 142-151, 2006.

[3] J. E. Hilliard, "The relationship between equity indices on world exchanges,” The Journal of Finance, vol. 34(1), pp. 103-114, 1979.

[4] S. Hu, "Hidden Markov Model and its application in finance," Wuhan: East China Normal University Press, 2014.

[5] S. Hu, L. Wu, "Large deviations for random dynamical systems and applications to hidden Markov models," Stochastic Processes and their Applications, vol. 121(1), pp. 61-90, Jan 2011. 
[6] S. Hu, "Transportation inequalities for hidden Markov chains and applications," Science China Mathematics, vol. 54(5), 1027-1042, 2011.

[7] Li H. International linkages of the Chinese stock exchanges: a multivariate GARCH analysis[J]. Applied Financial Economics, 2007, 17(4): 285-297.

[8] Z. Liu, S. Ren, and W. Li, "The research on the co-movement between Chinese stock market and world's major stock markets," Journal of Industrial Technological Economics, vol. 28(1), pp. 129-136, 2009.

[9] Q. Tang, and W. Cao, "Correlation dynamics between China, US and HK stock Returns," Statistical Research, vol. 26(2), pp. 21-27, 2009.

[10] H. Wu, G. Hu, and S. Qin, "Analysis of dependence in China and oversea stock markets under subprime crisis: based on Markov Switching Model,” Journal of Applied Statistics and Management, vol. 2, pp. 343-358, 2013.

[11] J. You, Z. Chen, and T. Zheng, "Economic integration and stock market linkages: analysis of the data based on relevant experience," Journal of Xiamen University (Arts \& Social Science), vol. 2, pp. 21-28, 2010.

[12] B. Zhang, Z. Fan, and X. Li, “Comovement between China and U.S.'s stock market,” Economic Research Journal, vol. 11, pp. 141-151, 2010. 